\title{
A Novel Unidirectional High-Gain Cascaded Square Ring Antenna for WLAN Base Station Applications
}

\author{
Subash Chandra YADAV ${ }^{1}$, V. SIVAVENKATESWARA RAO ${ }^{1}$, S. P. DUTTAGUPTA ${ }^{2}$ \\ ${ }^{1}$ Dept. of Electronics and Communication Engineering NIT Patna, Bihar, India \\ ${ }^{2}$ Dept. of Electrical Engineering IIT Bombay, India \\ subashiitkgp@gmail.com, sivarv.ra20.ec@nitp.ac.in, sdgupta@ee.iitb.ac.in
}

Submitted August 8, 2021 / Accepted October 28, 2021

\begin{abstract}
This paper designs a unidirectional high gain, low-cost cascading ring antenna with coaxial feeding and metal without the dielectric. The designed antenna suits for high power transfer applications such as radar communications, wireless local area network (WLAN), and base stations. The use of gap-coupled cascading rings in the design enhances the gain to $13.4 \mathrm{dBi}$ at the resonance frequency of $2.45 \mathrm{GHz}$, improving the side lobes level and front-to-back ratios. The proposed antenna has symmetrical half power beam width (HPBW) in H-plane and E-plane of 37 degree and 36.5 degree, respectively. The cross-polarization field component of the antenna below $-25 d B$ in H-plane, and below $-45 d B$ in E-plane is obtained from the measurements. The measured antenna has $10 \mathrm{~dB}$ bandwidth of $95 \mathrm{MHz}$ i.e., $2.405-2.50 \mathrm{GHz}$ that covers the ISM $2.45 \mathrm{GHz}$ band. The designed antenna is planar in structure with compact radiating rings of size $1.16 \lambda \times 0.4 \lambda \times 0.1 \lambda$. The measured and HFFS simulated results are found in good agreement.
\end{abstract}

\section{Keywords}

Cascaded square ring, high gain, metallic structure, symmetrical radiation pattern, wireless local area network (WLAN)

\section{Introduction}

In modern wireless communication systems, we require unidirectional high gain antennas for long-distance communication systems such as base stations, radar communications, and coal-mine applications. The antenna for such applications requires a unidirectional radiation pattern, high gain, low-cross polarization, symmetrical radiation pattern, low front-to-back ratio, and high-power handling capacity. The non-planar antenna can easily achieve wide bandwidth, but the planar structure is preferred because of its simple structure and easy fabrication process. Many high gain microstrip antennas have been studied in this literature survey. However, the conventional rectangular microstrip antenna has low gain and low power han- dling capacity because of the dielectric substrates [1], [2]. An antenna array technique is used to improve the gain of the microstrip antenna, but it requires the design of the feeding network that increases the antenna's cost, and the feeding network absorbs power too [3], [4]. Recently, some meta-material techniques have been used to enhance the gain of the microstrip antenna by reducing the dielectric constant through the air holes, but this approach makes design complex and has low power handling capacity compared to metallic antennas [5], [6]. The Yagi-Uda antenna array enhances the gain, but it requires directors, reflectors, and feed elements, which increases the design complexity and cost [7], [8]. The dielectric resonator antenna (DRA) gives wide bandwidth but low gain and low power handling capacity [9], [10]. Therefore, antenna array configurations are required to enhance the dielectric resonator antenna's gain, but it requires an external feeding network that increases antenna complexity and design cost [11], [12]. Thus, feeding network and dielectric materials should be avoided to reduce the cost and complexity of the antenna; hence, metallic antennas with a simple structure are preferred [13], [14]. The metallic antenna array reported in [15] has $10 \%$ impedance bandwidth and peak gain of $11.81 \mathrm{dBi}$, but it occupies a large volume $(3.5 \lambda \times 0.43 \lambda \times 0.26 \lambda)$, and it requires an external feeding network. The waveguide-fed antenna reported in [16] has $14 \%$ bandwidth and a high gain of $15 \mathrm{dBi}$, whereas it requires a bulky design that occupies a large volume, too. The dual-band metallic antenna reported in [17], [18] has a bandwidth of $10 \%$, but peak gain is smaller than $11 \mathrm{dBi}$.

The works, as mentioned above, require an external feeding network with low gain and low power handling capacity due to the use of dielectric substrates. In this paper, a high gain antenna is designed by cascading two-gapcoupled rings to the central ring antenna, and simple coaxial feeding is used for excitation. The four parallel arms of the cascading rings have in-phase current components; hence, these arms are the primary radiators. The outer arms have a small current compared to the middle arms. Thus, the directivity of the antenna is enhanced due to the reduction of the side lobes. The cascaded rings improve the HPBW in H-plane and make the radiation pattern symmetrical. The measurement antenna has a resonance frequency 
of $2.45 \mathrm{GHz}$ with $10 \mathrm{~dB}$ bandwidth from $2.405-2.500 \mathrm{GHz}$. The proposed antenna has a high gain of $13.4 \mathrm{dBi}$ at $2.450 \mathrm{GHz}$ with HPBW of 37 degree in H-plane and 36.5 degree in E-plane.

\section{Structure of the Primary Ring Antenna}

The primary square ring antenna structure is shown in Fig. 1, and its dimensions are indicated by the symbols. The square ring of inner side length $a$, width $w$, and thickness $0.5 \mathrm{~mm}$ is suspended at height $h$ on the circular ground plane of radius $R$. The side of the square ring, which is perpendicular to the $\mathrm{y}$-axis, is fed from a $50-\Omega$ coaxial probe and its opposite side is shorted to the ground plane through a shorting pin of radius $1 \mathrm{~mm}$. The structure of the primary ring antenna is simulated by taking dimensions ( $R=110 \mathrm{~mm}, a=46.5 \mathrm{~mm}, w=2.5 \mathrm{~mm}$, and $h=12 \mathrm{~mm}$ ). The simulated return loss and directivity are plotted in Fig. 2 and Fig. 3, respectively. As the height $h$ increases, the bandwidth is increased, while resonance frequency is shifted to the lower side, and the antenna's directivity is slightly reduced. The simulated resonance frequency of $2.54 \mathrm{GHz}$ with $10 \mathrm{~dB}$ bandwidth of $2.46-2.62 \mathrm{GHz}$ is observed with the directivity of $11 \mathrm{dBi}$ at resonance.

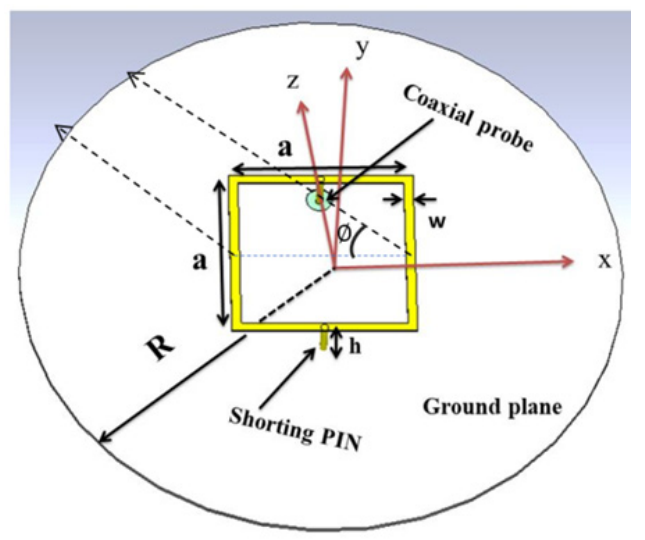

Fig. 1. The design structure of a primary ring antenna.

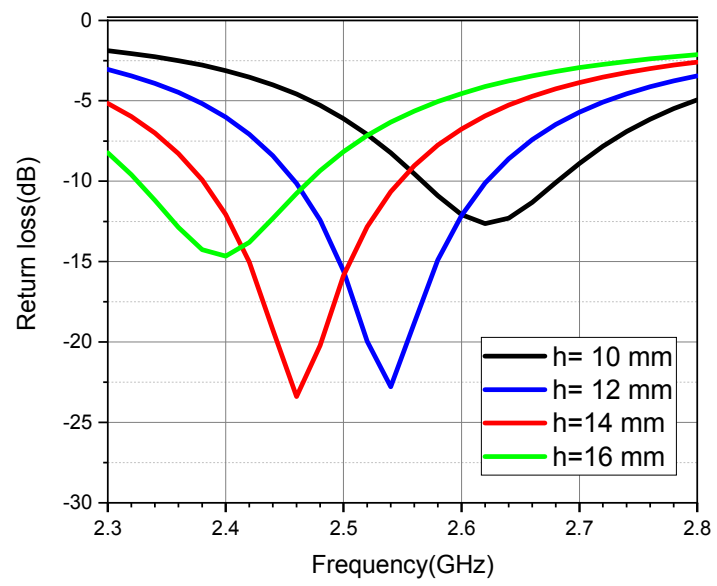

Fig. 2. The simulated return loss of the antenna with variation in height $h$.

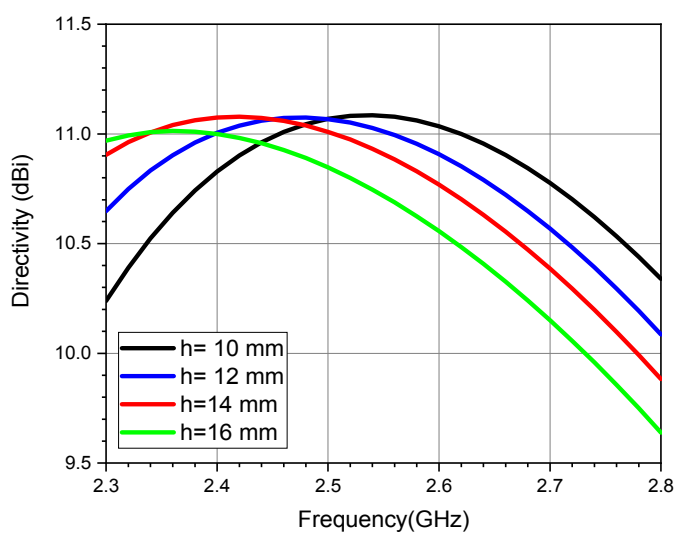

Fig. 3. Simulated directivity with variation in height $h$.

\section{Working Principle}

The current density of the proposed antennas is simulated at $2.54 \mathrm{GHz}$, and is shown in Fig. 4. The current flows from the coaxial probe to the ground plane through two non-fed arms and a shorting pin. The current path is indicated in Fig. 4, which shows that the total length traversed by the current is equal to the wavelength. Therefore, by equating the whole current path with wavelength yields the mathematical expression for the calculation of the resonance frequency of the primary ring antenna. The resonance frequency $2.54 \mathrm{GHz}$ is obtained from HFSS simulation and $2.56 \mathrm{GHz}$ is obtained from the analytical equation (1). Thus, the simulated and calculated resonance frequencies are approximately matched.

$$
2 a+2 h \approx \lambda \text { or } f \approx \frac{c}{2(a+h)}
$$

where $a$ is the side length of square ring, $c$ is the speed of light in free space, $h$ is the suspended height of the ring from the ground plane, $f$ is resonance frequency and $\lambda$ is free-space wavelength corresponding to the resonance frequency.

The normalized radiation pattern of the primary ring antenna simulated at resonance frequency $2.54 \mathrm{GHz}$, is shown in Fig. 5. The simulated antenna has broadside radi-

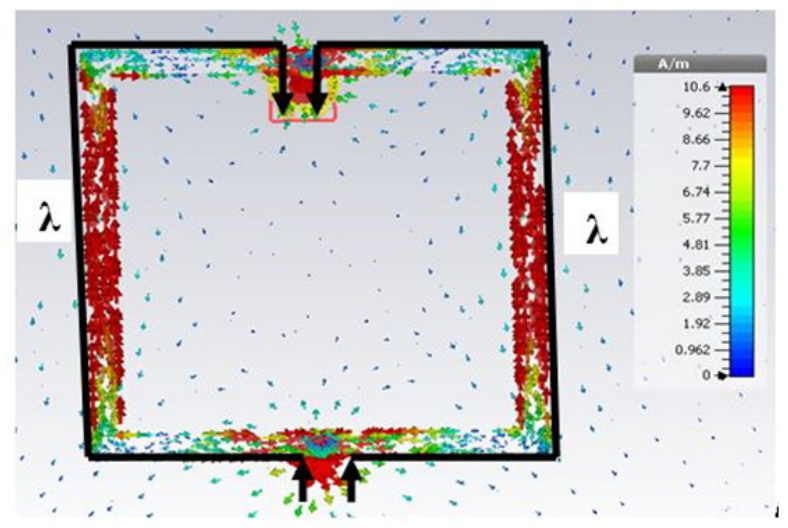

Fig. 4. Simulated surface current density at $2.54 \mathrm{GHz}$. 


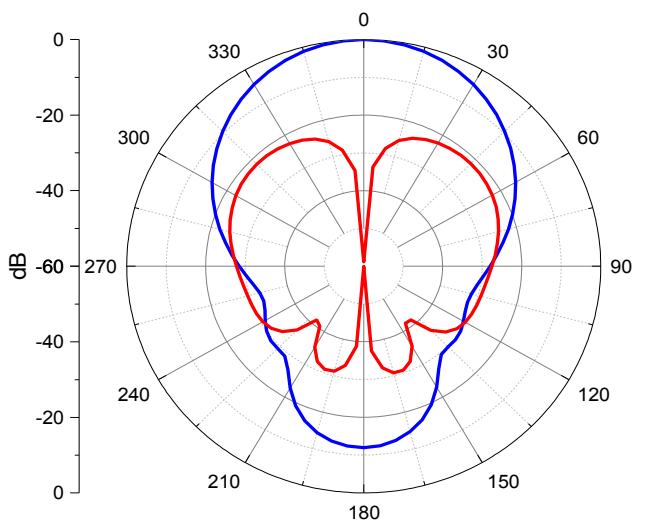

(a)

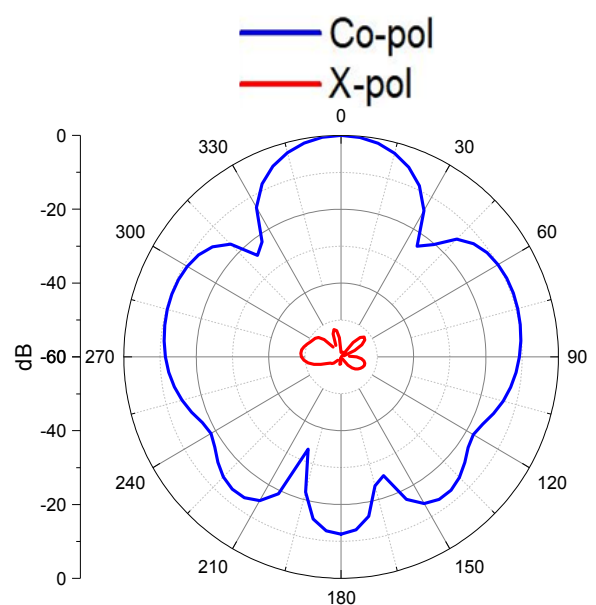

(b)

Fig. 5. Simulated radiation pattern at $2.54 \mathrm{GHz}$ (a) H-plane, (b) E-plane.

ation with low cross-polarization below $-22 \mathrm{~dB}$ in the $\mathrm{H}$-plane and below $-48 \mathrm{~dB}$ in E-plane. The simulated radiation pattern has asymmetrical half-power beam width (HPBW) of 50 degree in H-plane and 31 degree in E-plane. The side lobe level is below $-9 \mathrm{~dB}$ in E-plane, and there is no side lobe in H-plane. The antenna is unidirectional with front to back ratio of $12 \mathrm{~dB}$ at resonance frequency $2.54 \mathrm{GHz}$.

The far-field radiation mechanism of the proposed antenna is similar to a horizontally polarized $\lambda / 2$ dipole antenna placed at height $h$ above the ground plane, as shown in Fig. 6 [19]. In our design, two parallel non-feeding arms of the square ring radiate similar to the $\lambda / 2$ dipole

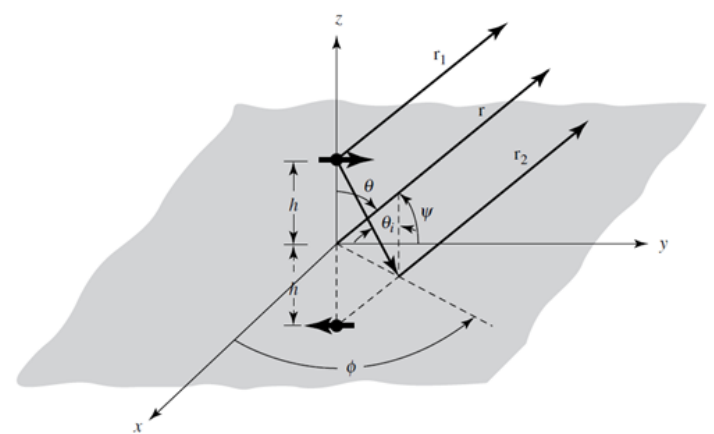

Fig. 6. The image of dipole antenna placed horizontally to the ground plane above height $h$ [19]. antenna with spacing $a$ between the two radiating sides. Therefore, the radiation pattern is similar to the two elements dipole array placed at height $h$ over the ground plane. We can derive the equation for maximum radiation intensity, radiated power, and directivity of a horizontal dipole antenna placed at height $h$ over the ground plane using equations (2)-(5) from [19].

$$
\begin{gathered}
U_{\max }=\frac{\eta}{2}\left(\frac{l I}{\lambda}\right)^{2} \sin ^{2}(k h) \text { for } h \leq \lambda / 4, \\
P_{\mathrm{rad}}=\eta \pi\left(\frac{l}{\lambda}\right)^{2}\left[\frac{2}{3}-\frac{\sin (2 k h)}{2 k h}-\frac{\cos (2 k h)}{(2 k h)^{2}}+\frac{\sin (2 k h)}{(2 k h)^{3}}\right], \\
D=\frac{4 \pi U_{\max }}{P_{\mathrm{rad}}}=\left\{4 \frac{\sin ^{2}(k h)}{R(k h)}\right\} \text { for } h \leq \frac{\lambda}{4}, \\
R(k h)=\left[\frac{2}{3}-\frac{\sin (2 k h)}{2 k h}-\frac{\cos (2 k h)}{(2 k h)^{2}}+\frac{\sin (2 k h)}{(2 k h)^{3}}\right] .
\end{gathered}
$$

Here, $k$ is propagation constant, $h$ is the height of the dipole antenna from the ground plane, $l$ is the length of the dipole antenna and $\eta$ is the wave impedance in free space $(120 \pi \Omega)$.

If height $h$ is equal to zero, then the dipole antenna is shorted with the ground plane, and it does not radiate, and similar things happen with the proposed antenna. The proposed antenna's radiation intensity is derived by multiplying the square of the array factor with the radiation intensity of the horizontal dipole antenna. The derived radiation intensity of the square loop antenna is given in (6).

$$
\begin{gathered}
U_{\max }=\frac{\eta}{2}\left(\frac{l I}{\lambda}\right)^{2} \sin ^{2}(k h) \cos ^{2}\left(\frac{k a}{2} \cos \Phi\right) \text { for } h \leq \lambda / 4, \\
U_{\max }=\frac{\eta}{2}\left(\frac{l I}{\lambda}\right)^{2} \frac{1}{2} \quad \text { for }\left\{h=\frac{\lambda}{8}, a=\frac{\lambda}{2} \text { and } \Phi=\frac{\pi}{2}\right\}, \\
U_{\max }=\frac{\eta}{2}\left(\frac{l I}{\lambda}\right)^{2} \text { for }\left\{h=\frac{\lambda}{4}, a=\frac{\lambda}{2} \text { and } \Phi=\frac{\pi}{2}\right\}, \\
P_{\text {rad }}=0 \quad \text { for }\left\{h=\frac{\lambda}{4}, a=\frac{\lambda}{2} \text { and } \Phi=\frac{\pi}{2}\right\} .
\end{gathered}
$$

The maximum radiation intensity of the square ring antenna is zero if $h$ is very small. Therefore, we chosen $h=\lambda / 8$ and $a=\lambda / 2$ and $\Phi=\pi / 2$ in our design to obtained radiation intensity given by $(7)$. The maximum radiation intensity can be received if we select $h=\lambda / 4$; however, the radiated power is zero; therefore antenna does not radiate effectively.

\section{Gain Enhancement by Cascading Rings}

The primary square ring antenna design discussed in the preceding section has a directivity of $\sim 11 \mathrm{dBi}$ at reso- 
nance frequency $2.54 \mathrm{GHz}$. In this section, the directivity of the primary square ring antenna is improved with two inphase cascaded rings. The structure of the proposed cascaded antenna is shown in Fig. 7.

When the primary ring antenna is simulated, it has only two sides with a common mode current; hence, these sides radiate like a horizontal dipole antenna placed at height $h$ over the ground plane, and its collective effect enhances the directivity. However, the cascaded ring antenna has two extra gap-coupled rings.

Therefore, the cascaded ring antenna has four parallel sides, which has an in-phase current, and these parallel sides radiate like four elements horizontal dipole array over the ground plane and enhance the directivity. The return loss of the cascading ring antenna is simulated with a variation of the gap $G$, the result is shown in Fig. 8. When there is no gap between the arms, i.e., $G=0 \mathrm{~mm}$, then the current flows from the coaxial probe to the shorting pin through the inner loop and outer loop and impedance is matched at the frequency of the outer loop. Hence the resonance frequency is determined by equating the circumference of the outer loop with wavelength, which is at $1.8 \mathrm{GHz}$, as obtained from HFSS simulation.

If a gap $G$ is created in the outer arms of the cascaded ring antenna then the current's significant components flow from the coaxial probe to the shorting pin through the sides of the middle ring. Hence resonance frequency is due to the

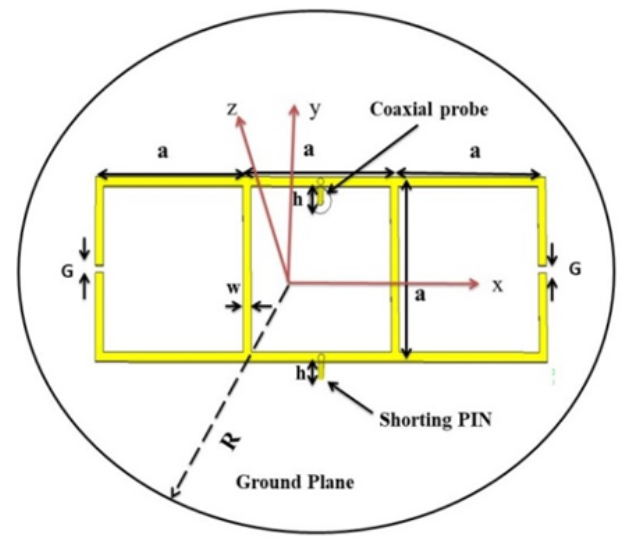

Fig. 7. The structure of the proposed cascaded ring antenna.

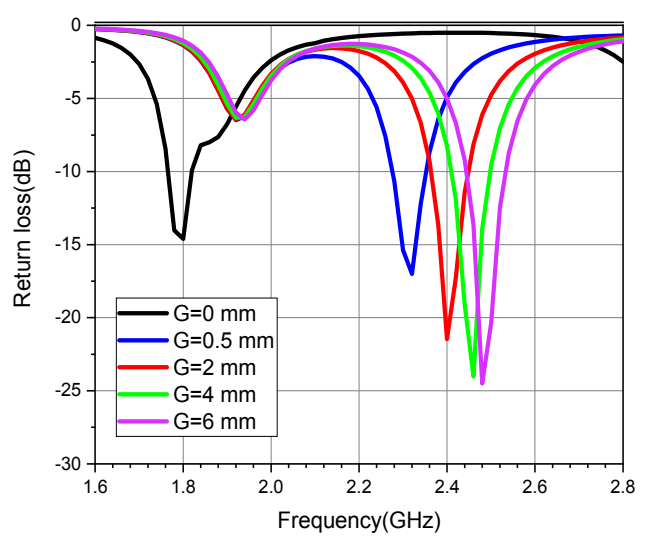

Fig. 8. Simulated return loss with a variation of $G$. central primary ring, which is identical to the resonance frequency of the primary ring antenna derived in (1), but a slight shift in resonance frequency is occurred due to the change of reactive part of the impedance of the cascaded antenna. For example, the $G=4 \mathrm{~mm}$ antenna has a resonance frequency of $2.45 \mathrm{GHz}$, closer to $2.54 \mathrm{GHz}$, the resonance frequency of the primary ring antenna. As the gap $G$ increases, less current flows in the outer side, and the majority of the current flows in the inner loop; hence the resonance frequency is shifted toward the resonance frequency of the primary ring antenna. The antenna simulated for $G=6 \mathrm{~mm}$ has a resonance frequency of $2.48 \mathrm{GHz}$. The surface current density of the proposed cascaded antenna is simulated at $2.45 \mathrm{GHz}$, which is shown in Fig. 9.

The current flows in all the parallel sides are in phase; hence these sides are the main radiating elements. The current flow in the antenna structure is drawn in Fig. 10. The broadside directivity of the antenna is simulated with

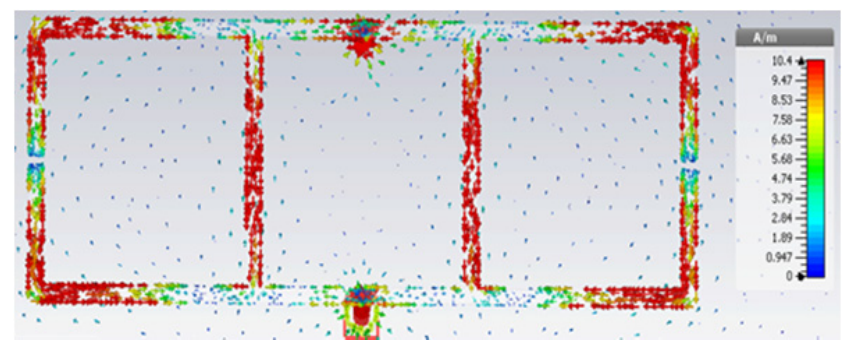

Fig. 9. Simulated surface current density at $2.45 \mathrm{GHz}$.

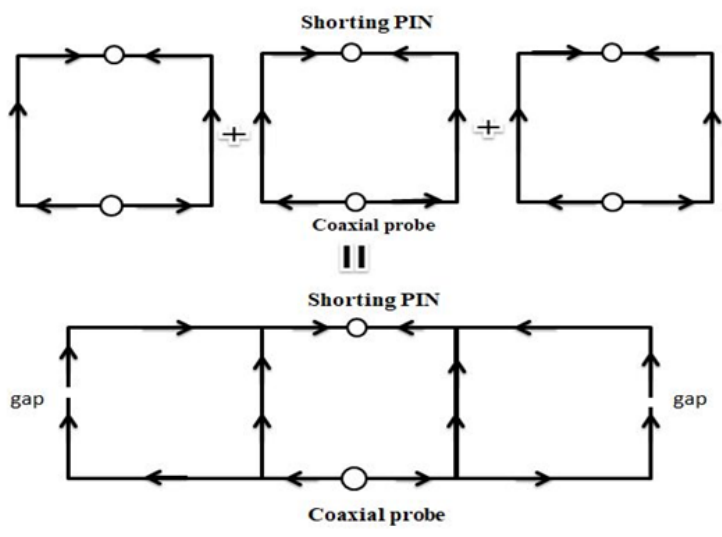

Fig. 10. Principle of the proposed cascaded antenna structure.

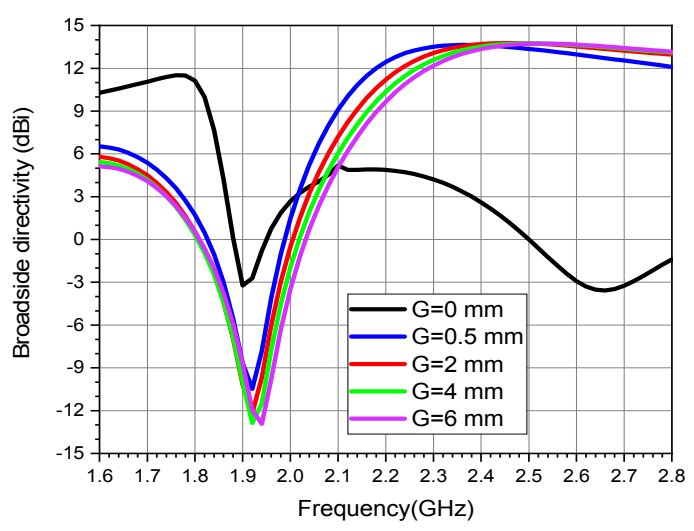

Fig. 11. Simulated directivity with variation in gap $G$. 


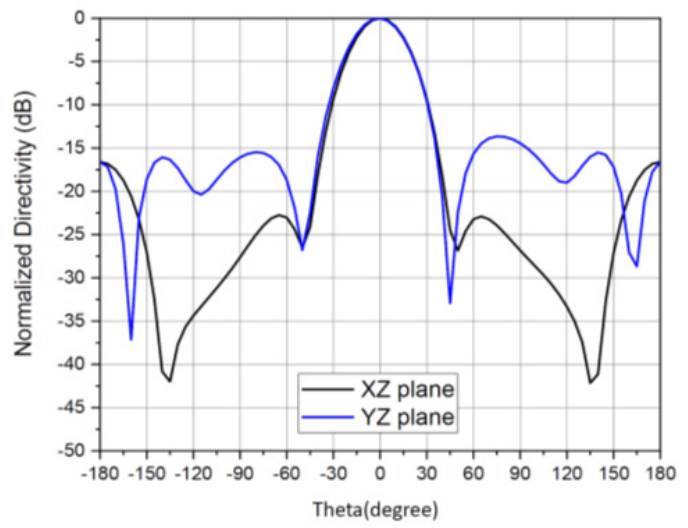

Fig. 12. Simulated 2-D radiation pattern at $2.45 \mathrm{GHz}$.
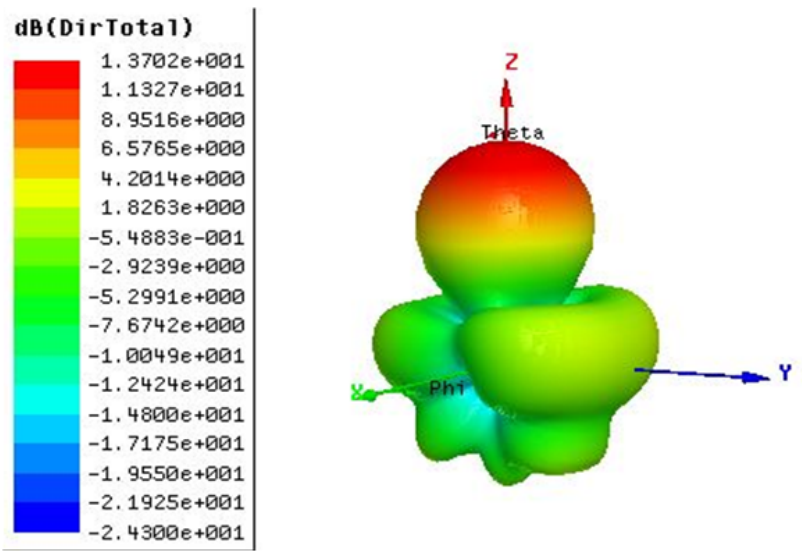

Fig. 13. Simulated 3-D radiation pattern at $2.45 \mathrm{GHz}$.

variation in $G$, as shown in Fig. 11 , when $G=0 \mathrm{~mm}$, then the directivity is $11.9 \mathrm{dBi}$ at the resonance frequency of $1.8 \mathrm{GHz}$. While gap $G$ increases, the resonance frequency is shifted at the higher side, and the antenna's directivity reaches $13.7 \mathrm{dBi}$ at $2.45 \mathrm{GHz}$ for the gap $G=3 \mathrm{~mm}$. There is a $1.80 \mathrm{~dB}$ improvement in directivity which is due to a reduction in side lobe level.

The simulated antenna with the single ring has asymmetrical HPBW with 52 degree in H-plane and 31 degree in E-plane. The HPBW improved and became symmetrical by introducing the cascading rings. The cascaded antenna with 35 degree HPBW in H-plane, and 36 degree HPBW in E-plane is obtained from the HFSS simulation, as shown in Fig. 12. The cascading ring improved the front-to-back ratio $17 \mathrm{~dB}$, and side lobe level below $13 \mathrm{~dB}$, in E-plane and the side lobe below $22 \mathrm{~dB}$ in H-plane as obtained from the simulation. In Fig. 13, the antenna's 3-D radiation pattern is simulated at $2.45 \mathrm{GHz}$, and the antenna has a directivity of $13.7 \mathrm{dBi}$, and the side lobe is reduced in the direction of cascading rings (H-plane).

\section{Fabrication and Measurements}

The cascading ring antenna prototype is shown in Fig. 14. It has been fabricated from a copper sheet of a thickness of $0.5 \mathrm{~mm}$. A simple 50-ohm SMA connector feeds the middle ring, and its opposite side is shorted to the

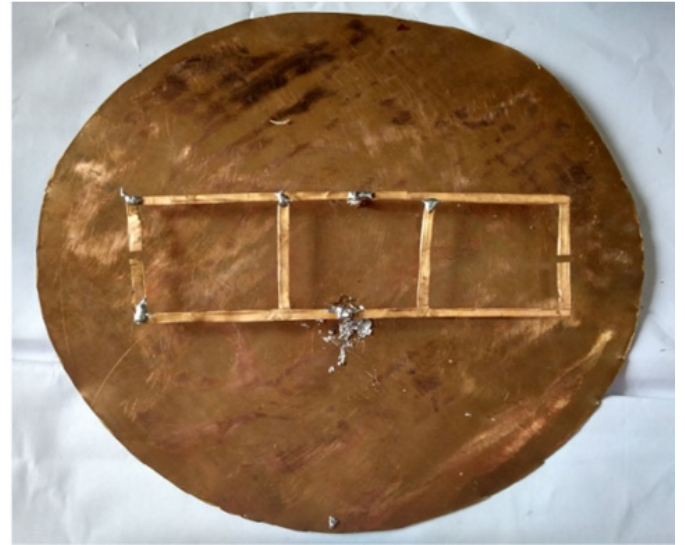

(a)

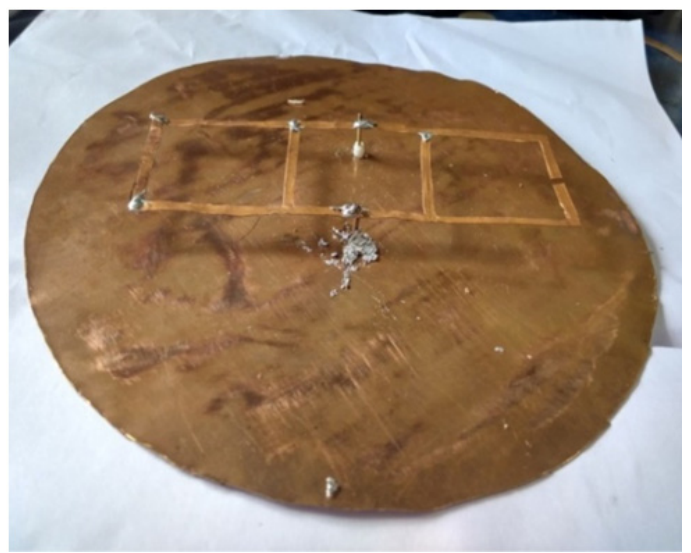

(b)

Fig. 14. Prototype of the proposed antenna: (a) Top view, (b) side view.

ground plane through a pin of radius $1 \mathrm{~mm}$. The soldering of the coaxial probe and shorting pin provides the support to suspend at height $h$ of the cascading ring over the circular ground plane. The antenna is fabricated with dimensions of radiating rings: $a=44 \mathrm{~mm}, w=2.5 \mathrm{~mm}, G=$ $4 \mathrm{~mm}, h=12 \mathrm{~mm}$, and $R=110 \mathrm{~mm}$. The designed antenna has advantages of being planar in structure, fabricated with metal only, small area occupied by radiating elements, simple feeding, and high power handling capacity due to metallic structure.

The return loss of the proposed antenna is simulated and measured using a vector network analyzer, and measurement and simulated results are mentioned in Fig. 15. The results show that the simulated antenna has a $10-\mathrm{dB}$ impedance bandwidth from $2.410-2.495 \mathrm{GHz}$ with a resonance frequency of $2.45 \mathrm{GHz}$. However, the measured antenna has a 10-dB impedance bandwidth from $2.405 \mathrm{GHz}$ to $2.50 \mathrm{GHz}$ with a resonance frequency of $2.45 \mathrm{GHz}$.

The gain of the proposed antenna is measured from a two-port vector network analyzer in an anechoic chamber. The reference antenna (double ridged waveguide horn antenna) is first connected to port 2, and the proposed cascaded ring antenna is connected to port 1 . We activate $S_{21}$ for the frequency range $(2.3-2.6 \mathrm{GHz})$. After this, we normalized the calibration, which gives $0 \mathrm{~dB} \mathrm{~S}_{21}$ over the selected sweep. This means the gain is now normalized to the 
reference antenna. Now we replace the reference antenna at port 1 and the proposed cascaded antenna at port 2, and we measured $\mathrm{S}_{21}$, which is the gain of the proposed cascaded antenna concerning the reference antenna. Hence the gain of the proposed antenna can be determined by (10).

$$
G_{\text {cascaded }}=S_{21}+G_{\text {ref. }}
$$

Here $G_{\text {cascaded }}$ is the gain of the proposed cascaded antenna and $G_{\text {ref }}$ is the gain of the reference antenna. The gain of the reference antenna $G_{\text {ref }}$ is $9.8 \mathrm{dBi}$ at $2.45 \mathrm{GHz}$, and $S_{21}$ is

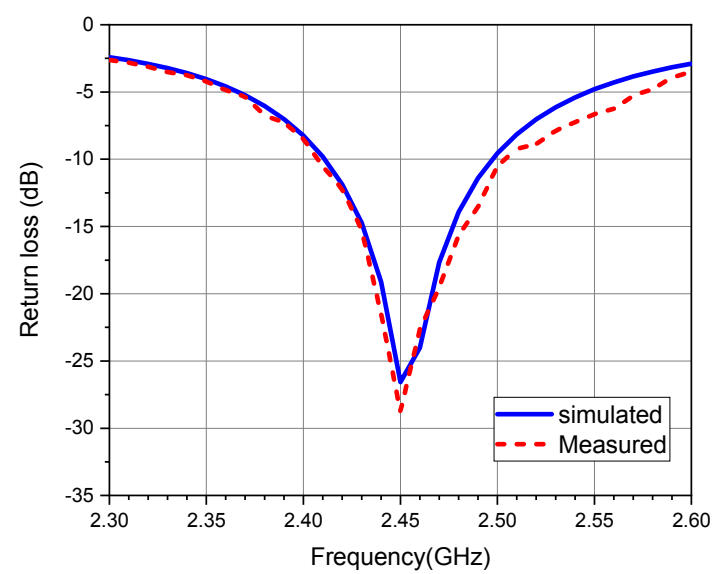

Fig. 15. The simulated and measured return loss of the cascaded antenna.

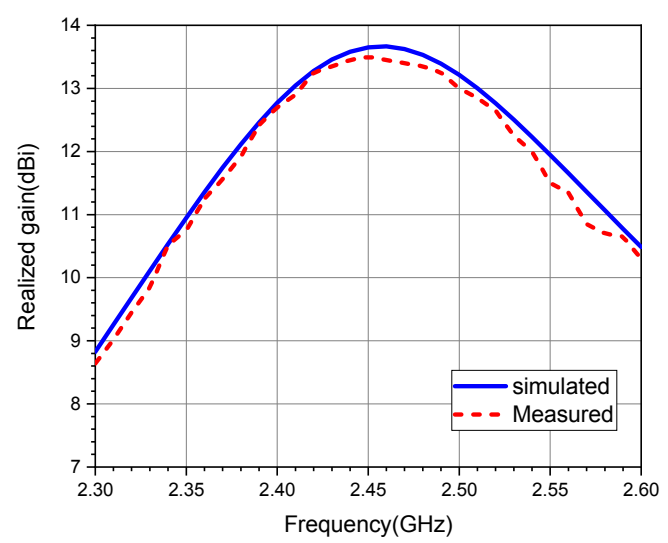

Fig. 16. The simulated and measured realized gain of the cascaded antenna.

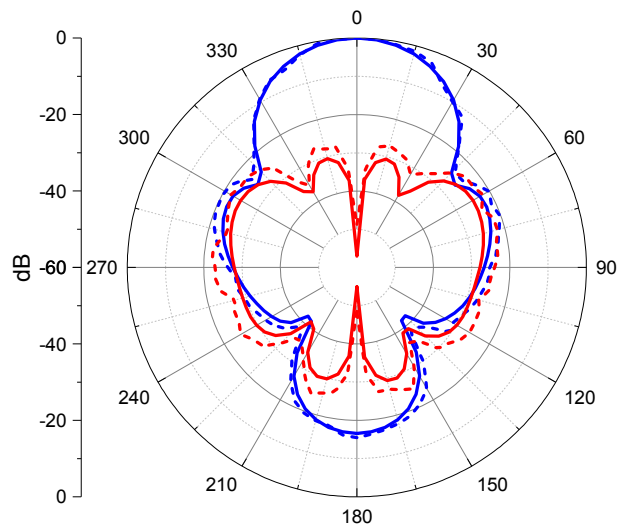

(a)

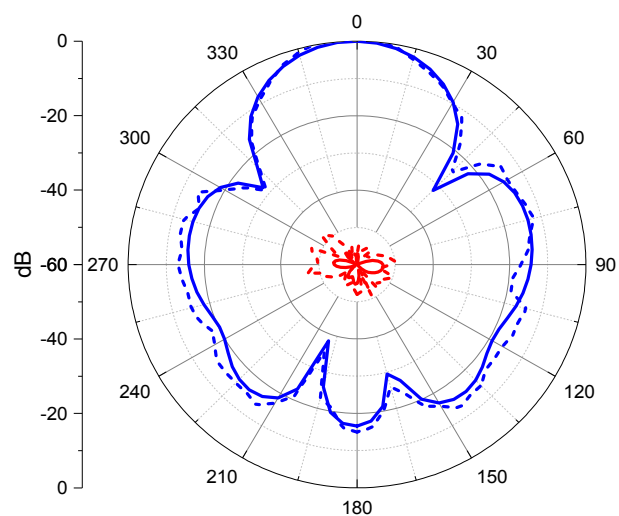

(b)

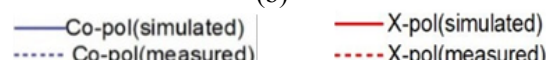

Fig. 17. The simulated and measured normalized radiation pattern at $2.45 \mathrm{GHz}$ : (a) H-plane, (b) E-plane.

3.6 dB obtained from the measurements; hence the gain of the measured antenna is $13.4 \mathrm{dBi}$ from (10). The measured broadside gain is matched with the HFSS simulated gain of $13.6 \mathrm{dBi}$ as shown in Fig. 16.

The normalized radiation pattern of the antenna is simulated and measured in H-plane at $2.45 \mathrm{GHz}$, as shown in Fig. 17(a).The simulated antenna has a low cross-polarization level below $-30 \mathrm{~dB}$, in H-plane and the cross-polarization level below $-40 \mathrm{~dB}$, is obtained in E-plane, as shown in Fig. 17(b).

\begin{tabular}{|c|c|c|c|c|c|}
\hline Ref. & Total planar area \& Total height & Resonance frequency \& 10-dB bandwidth & Peak gain & $\begin{array}{c}\text { Dielectric } \\
\text { constant }\end{array}$ & Feeding technique \\
\hline$[16]$ & $4 \lambda^{2} \& 0.93 \lambda$ & $5.8 \mathrm{GHz} \& 14 \%(5.40-6.20 \mathrm{GHz})$ & $15 \mathrm{dBi}$ & 1 & Wave-guide feeding \\
{$[20]$} & $1.1 \lambda^{2} \& 0.11 \lambda$ & $2.45 \mathrm{GHz} \& 11.4 \%(2.26-2.54 \mathrm{GHz})$ & $11.7 \mathrm{dBi}$ & 3.55 & Feeding network \\
\hline$[21]$ & $1.316 \lambda^{2} \& 0.048 \lambda$ & $2.9 \mathrm{GHz} \& 13 \%(2.83-3.22 \mathrm{GHz})$ & $10.5 \mathrm{dBi}$ & 2.2 & Coaxial probe \\
\hline$[22]$ & $9.57 \lambda^{2} \& \lambda$ & $5.6 \mathrm{GHz} \& 5.3 \%(5.45-5.75 \mathrm{GHz})$ & $14.8 \mathrm{dBi}$ & 1 & Coaxial probe \\
\hline$[23]$ & $1.06 \lambda^{2} \& 3.17 \lambda$ & $5.6 \mathrm{GHz} \& 17.8 \%(5.10-6.10 \mathrm{GHz})$ & $16.7 \mathrm{dBi}$ & 2.2 & Waveguide feeding \\
\hline This work & $2.53 \lambda^{2} \& 0.1 \lambda$ & $2.45 \mathrm{GHz}, 3.87 \%(2.405-2.50 \mathrm{GHz})$ & $13.4 \mathrm{dBi}$ & 1 & Coaxial probe \\
\hline
\end{tabular}

Tab 1. Comparisons of the proposed high gain antenna and previously reported high gain antennas. 


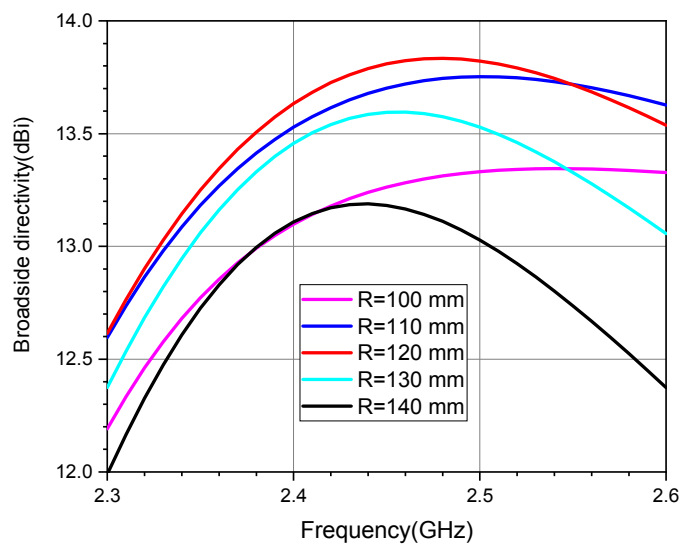

Fig. 18. Effect of the ground plane radius $R$ on broadside directivity.

The measured antenna has a cross-polarization level below $-25 \mathrm{~dB}$, HPBW, and 36.5 degree in H-plane. The cross-polarization level below $-40 \mathrm{~dB}$ and HPBW $37 \mathrm{de}-$ gree are measured in E-plane, and the antenna is unidirectional with a front-to-back ratio of $15 \mathrm{~dB}$. The measured results are in good agreement with simulated results. There is a slight deviation in simulated and measured results due to fabrication and measurement errors.

A performance comparison of various reported antennas in the literature along with the proposed antennas is tabulated in Tab. 1. The proposed design shows good enactment over existed ones.

\section{Effect of Ground Plane Size}

In this section, the performance of the proposed antenna is studied concerning changes in the radius of the ground plane. In Fig. 18, we have simulated the broadside directivity of the proposed antenna regarding the ground plane radius $R$. The simulated broadside directivity of the antenna is shown in Fig. 18. The directivity is increased as the ground plane radius increases from $R=100 \mathrm{~mm}$ to $R=120 \mathrm{~mm}$ due to the enhancement of the effective area. However, the broadside directivity of the antenna decreases as the ground plane size increases from $R=120 \mathrm{~mm}$ to $R=140 \mathrm{~mm}$ due to destructive interference from the large open-ended ground plane.

\section{Conclusion}

This paper proposed a high gain antenna for radar communication, WLAN applications, base stations, and energy harvesting applications. The antenna structure is simple and designed from copper, and less complex coaxial feeding is used for the excitation. In the proposed antenna, in-phase cascading rings are used for gain enhancements. The designed antenna has a high gain of $13.4 \mathrm{dBi}$ with a symmetrical radiation pattern in the $\mathrm{E}$ and $\mathrm{H}$ planes at the resonance frequency. The operating principle of the proposed antenna is explained using four elements horizontal dipole antenna array placed over the ground plane.

\section{References}

[1] ZELENCHUK, D. E., FUSCO, V. F. Planar high-gain WLAN PCB antenna. IEEE Antennas and Wireless Propagation Letters, 2009, vol. 8, p. 1314-1316. DOI: 10.1109/LAWP.2009.2037718

[2] VAN ROOYEN, M., ODENDAAL, J. W., JOUBERT, J. Highgain directional antenna for WLAN and WiMAX applications. IEEE Antennas and Wireless Propagation Letters, 2017, vol. 16, p. 286-289. DOI: 10.1109/LAWP.2016.2573594

[3] TOH, W. K., QING, X., CHEN, Z. N. A planar dual-band antenna array. IEEE Transactions on Antennas and Propagation, 2011, vol. 59, no. 3, p. 833-838. DOI: 10.1109/TAP.2010.2103039

[4] BUFFI, A., SERRA, A. A., NEPA, P., et al. A focused planar microstrip array for $2.4 \mathrm{GHz}$ RFID readers. IEEE Transactions on Antennas and Propagation, 2010, vol. 58, no. 5, p. 1536-1544. DOI: 10.1109/TAP.2010.2044331

[5] LIAN, R., TANG, Z., YIN, Y. Design of a broadband polarizationreconfigurable Fabry-Perot resonator antenna. IEEE Antennas and Wireless Propagation Letters, 2018, vol. 17, no. 1, p. 122-125. DOI: 10.1109/LAWP.2017.2777502

[6] JI, L. Y., QIN, P. Y., GUO, Y. J., et al. A wideband polarization reconfigurable partially reflective surface antenna. IEEE Transactions on Antennas Propagation, 2016, vol. 64, no. 10, p. 4534-4538. DOI: 10.1109/TAP.2016.2593716

[7] DEJEAN, G. R., THAI, T. T., NIKOLAOU, S., et al. Design and analysis of microstrip bi-Yagi and quad-Yagi antenna arrays for WLAN applications. IEEE Antenna and Wireless Propagation Letters, 2007, vol. 6, p. 244-248. DOI: 10.1109/LAWP.2007.893104

[8] TAO, J., FENG, Q., LIU, T. Dual-wideband magnetoelectric dipole antenna with director loaded. IEEE Antennas and Wireless Propagation Letters, 2018, vol. 17, no. 10, p. 1885-1889. DOI: 10.1109/LAWP.2018.2869034

[9] NASIMUDDIN, ESSELLE, K. P. A low-profile compact microwave antenna with high gain and wide bandwidth. IEEE Transactions on Antennas and Propagation, 2007, vol. 55, no. 6, p. 1880-1883. DOI: 10.1109/TAP.2007.898644

[10] PAN, Y. M., ZHENG, S. Y. A low-profile stacked dielectric resonator antenna with high-gain and wide bandwidth. IEEE Antennas and Wireless Propagation Letters, 2016, vol. 15, p. 68-71. DOI: 10.1109/LAWP.2015.2429686

[11] FAKHTE, S., ORAIZI, H., MATEKOVITS, L. Gain improvement of rectangular dielectric resonator antenna by engraving grooves on its side walls. IEEE Antennas and Wireless Propagation Letters, 2017, vol. 16, p. 2167-2170. DOI: 10.1109/LAWP.2017.2702584

[12] MRNKA, M., RAIDA, Z. Enhanced-gain dielectric resonator antenna based on the combination of higher-order modes. IEEE Antennas and Wireless Propagation Letters, 2016, vol. 15, p. 710-713. DOI: 10.1109/LAWP.2015.2470099

[13] RANJBAR NIKKHAH, M., RASHED-MOHASSEL, J., KISHK, A. A. High-gain aperture coupled rectangular dielectric resonator antenna array using parasitic elements. IEEE Transactions on Antennas and Propagation, 2013, vol. 61, no. 7, p. 3905-3908. DOI: 10.1109 /TAP.2013.2254451

[14] GUO, S. J., WU, L. S., LEUNG, K. W., et al. Microstrip-fed differential dielectric resonator antenna and array. IEEE Antennas and Wireless Propagation Letters, 2018, vol. 17, no. 9, p. 1736-1739. DOI: 10.1109/LAWP.2018.2864972

[15] HOU, Y., LI, Y., ZHANG, Z., ISKANDER, M. F. All-metal endfire antenna with high gain and stable radiation pattern for the platform-embedded application. IEEE Transactions on Antennas and Propagation, vol. 67, no. 2, p. 730-737. DOI: 10.1109/TAP.2018.2879822 
[16] GHOlAmi, M., AMAYA, R. E., YAGOUB, M. C. A Compact and high-gain cavity-backed waveguide aperture antenna in the $\mathrm{C}$ band for high-power application. IEEE Transactions on Antennas and Propagation, 2018, vol. 66, no. 3, p. 1808-1816. DOI: 10.1109/TAP.2018.2794412

[17] ZHAI, H., GAO, Q., LIANG, C., et al. A dual-band high-gain base-station antenna for WLAN and WiMAX applications. IEEE Antennas and Wireless Propagation Letters, 2014, vol. 13, p. 876-879. DOI: 10.1109/LAWP.2014.2321503

[18] LIU, P., FENG, H., LI, Y., et al. Low-profile endfire leaky-wave antenna with air media. IEEE Transactions on Antennas and Propagation, 2018, vol. 66, no. 3, p. 1086-1092. DOI: 10.1109/TAP.2018.2790042

[19] BALANIS, C. A. Antenna Theory: Design and Analysis. $4^{\text {th }}$ ed. New York (USA): Wiley, 2016. ISBN: 9781118642061

[20] CAI, X., GEYI, W., SUN, H. A printed dipole array with high gain and endfire radiation. IEEE Antennas and Wireless Propagation Letters, 2017, vol. 16, p. 1512-1515. DOI: 10.1109/LAWP.2016.2647319

[21] ALHARBI, M., BALANIS, C. A., BIRTCHER, C. R., et al. Hybrid circular ground planes for high-realized-gain low-profile loop antennas. IEEE Antennas and Wireless Propagation Letters, 2018, vol. 17, no. 8, p. 1426-1429. DOI: 10.1109/LAWP.2018.2848840

[22] KUMAR, C., SRINIVASAN, V. V., LAKSHMEESHA, V. K., et al. Design of short axial length high gain dielectric rod antenna. IEEE Transaction on Antennas and Propagation, 2010, vol. 58, no. 12, p. 4066-4069. DOI: 10.1109/TAP.2010.2078457

[23] WANG, H., LIU, S. F., CHEN, L., et al. Gain enhancement for broadband vertical planar printed antenna with $\mathrm{H}$-shaped resonator structures. IEEE Transactions on Antennas and Propagation, 2014, vol. 62, no. 8, p. 4411-4415. DOI: 10.1109/TAP.2014.2325955

\section{About the Authors...}

Subash Chandra YADAV received his B.Tech. degree in Electronics and Communication Engineering from BIET
Jhansi, India, in 2011 and M.Tech. in RF \& Microwave Engineering from IIT Kharagpur in 2013. He worked as an Assistant Professor in the Department of Electronics and Communication Engineering at MANIT Bhopal from 2014 to 2015. He has completed his Ph.D. degree in the Department of Electrical Engineering at IIT Bombay in 2021, and his research area is broadband high gain coupled and cascaded ring antennas. Recently, he joined the Electronics and Communication Engineering Department at the National Institute of Technology Patna, India as an Assistant Professor. He has published 6 SCI and Scopus index journal papers.

V. SIVAVENKATESWARA RAO received his B.Tech. degree in Electronics and Communication Engineering from JNTU Hyderabad, India in 2008, and M.Tech. in Digital Systems from MNNIT Allahabad in 2012. He has completed his Ph.D. degree in the Department of Electronics Engineering at IIT (BHU) Varanasi in 2019 in Microwave Engineering, and his research area is design and analysis of RF sources and cascaded ring antennas. Recently, he joined the Electronics and Communication Engineering Department at the National Institute of Technology Patna, India as a Research Associate. He has published 4 SCI and Scopus index journal papers.

S. P. DUTTAGUPTA obtained his B.Tech. (Honors) in Electronics from IIT Kharagpur, India, and his Ph.D. from the University of Rochester, Rochester, New York, USA. Currently, he is working as a Professor in the Electrical Engineering Department at the Indian Institute of Technology Bombay 400076. His research area is $\mathrm{THz}$ absorber and photoconductive antennas design. He has published more than $150 \mathrm{SCI}$ index journal papers. 